Çukurova Üniversitesi Mühendislik Mimarlık Fakültesi Dergisi, 31(2), ss. 187-194, Aralık 2016

Çukurova University Journal of the Faculty of Engineering and Architecture, 31(2), pp. 187-194, December 2016

\title{
Donatı Tabakasının Optimum Derinliğinin Farklı Temel Şekilleri için Değerlendirilmesi
}

\author{
Baki BAĞRIAÇIK ${ }^{* 1}$ \\ ${ }^{1}$ Çukurova Üniversitesi, Mühendislik Mimarlık Fakültesi, İnşaat Mühendisliği Bölümü, Adana
}

Geliş tarihi: 03.06.2016 Kabul tarihi: 23.11.2016

Öz

Bu çalışmada, şerit bir temel $(B=10 \mathrm{~cm})$ altında, donatı tabakası ile güçlendirilmiş zeminlerdeki ilk donatı tabakasının optimum derinliği, yükleme ve gerilme açısından deneysel olarak belirlenmiştir. Deneylerde, sabit bir derinlikte kum tabakası hazırlanarak, temelden dolayı oluşan donatısız ve donatılı durumlarda, temel genişliğinin 2,0 katı $(\mathrm{Z}=2.0 \mathrm{~B})$ derinlikte meydana gelen gerilme değerleri basınç algılayıcıları yardımıyla ölçülmüştür. Donatısız durumda ölçülen gerilme değerleri, temel tabanından itibaren farklı derinliklere $(\mathrm{U}=0,10 \mathrm{~B}, \mathrm{U}=0,15 \mathrm{~B}, \mathrm{U}=0,20 \mathrm{~B}, \mathrm{U}=0,25 \mathrm{~B}, \mathrm{U}=0,30 \mathrm{~B}, \mathrm{U}=0,35 \mathrm{~B}$ ve $\mathrm{U}=0,40 \mathrm{~B})(\mathrm{U}=$ geogridin temel tabanından itibaren derinliği, $B=$ temel genişliği, $Z=$ kum tabakası derinliği) yerleştirilen tek sıra geogrid donatı tabakası olması durumunda, meydana gelen gerilme değerleri ile karşılaştırılmıştır. Ayrıca, farklı temel şekillerinin ilk donatı tabakasının optimum derinliğine etkisini bir arada gösterebilmek amacıyla, literatürde yapılmış olan çalışmalarla karşılaştırılmıştır. Sonuçta, şerit temel için ilk donatı tabakasının optimum derinliği yaklaşık $\mathrm{U}=0,30 \mathrm{~B}$ olarak bulunmuş ve temel şeklinin farklı olmasının da bu derinliği değiştirdiği belirlenmiştir.

Anahtar Kelimeler: Model deney, Donatı tabakası optimum derinliği, İlave düşey gerilme, Basınç algılayıcı, Farklı temel şekilleri

\section{Evaluation of the Reinforcement Layer's Optimum Depth under Different Shape of Footing}

\begin{abstract}
In this study, additional vertical stresses, which occur in a soil as a result of uniformly loaded strip footing, resting on sandy soils unreinforced and reinforced by geogrids, have been investigated by laboratory model tests. Additional vertical stress values that occur on a horizontal planes of particular specified depths, have been measured with pressure transducers. The additional vertical stresses have been measured in the fixed depth $(\mathrm{Z}=2.0 \mathrm{~B})$, by replacing the geogrid's depth. Geogrid, which placed into the depths of $\mathrm{U}=0.10 \mathrm{~B}, \mathrm{U}=0.15 \mathrm{~B}, \mathrm{U}=0.20 \mathrm{~B}, \mathrm{U}=0.25 \mathrm{~B}, \mathrm{U}=0.30 \mathrm{~B}, \mathrm{U}=0.35 \mathrm{~B}$ and $\mathrm{U}=0.40 \mathrm{~B}$ ( $\mathrm{U}=\mathrm{depth}$ of geogrid from foundation, $\mathrm{B}=$ width of footing, $\mathrm{Z}=$ depth of sandy soil ) at soil, have been used in the tests. According to test results, it has seen that the geogrid's optimum depth is approximately $U=0.30 \mathrm{~B}$ for strip footings and this depth is changed with the different shape of footings.
\end{abstract}

Keywords: Model tests, Reinforcement layer's optimum depth, Additional soil stress, Stress transducer, Different shape of footing

\footnotetext{
*Sorumlu yazar (Corresponding author): Baki BAĞRIAÇIK, bbagriacik@cu.edu.tr
} 


\section{GİRIŞ}

Zeminler çok değişken malzemelerden oluştukları için, zemin mekaniği ve temel mühendisliği problemlerinde zeminlerin endeks, mukavemet ve oturma gibi özelliklerinin iyi analiz edilmesi gerekmektedir. Bunun yanı sıra, zemine etki eden yer alt1 suyu, deprem vb. parametrelerin de dikkate alınması gerekmektedir. Birçok inşaat malzemesi için, tasarım ve uygulama problemlerinin çözümünde belirli katsayılar kullanılarak malzeme davranışının belirlenmesi mümkün olmaktadır. Fakat zemin ile ilgili problemlerde kullanılacak malzeme özelliklerinin hangi koşullarda belirlendiği ve geçerliliğini koruduğunu anlamadan, bu problemler için güvenli ve ekonomik mühendislik çözümleri elde etmek mümkün olamamaktadır. $\mathrm{Bu}$ durum, zemin mekaniği ve temel mühendisliğinin önemini daha da artırmaktadır [1].

Yap1 yükleri, zemin yüzeyine temellerle iletildiğinden, zemin içerisinde oluşan ilave gerilmelerden dolayı özellikle yükün etkidiği bölgeye yakın kısımlarda fazla olmak üzere, şekil değiştirmeler meydana gelir. Oluşan gerilmelerin şiddetinin ve dağılımının iyi bilinmesi, birçok problemin çözümü ve projelerin tasarımında oldukça önemlidir [2].

Bilim ve teknolojinin gelişmesine ve hızla artış gösteren dünya nüfusuna bağlı olarak, yumuşakgevşek zeminlerde çok katlı yüksek binaların projelendirilmesi zorunluluğu gittikçe önem kazanmaktadır.

Durumun böyle olması, ya derin temel sistemine geçilmesini ya da temel zemininde iyileştirme yapılmasını zorunlu hale getirmektedir. Özellikle ekonomik olması sebebiyle, zemin iyileştirme yöntemlerinden, donatılı zemin uygulaması sıklıkla kullanılmaktadır [4].

Donatılı zemin uygulamasında, en önemli hususlardan biri donatının temel tabanından itibaren hangi derinlikte uygulanması gerektiğidir.
$\mathrm{Bu}$ çalışmada, donatısız ve donatı ile güçlendirilmiş kumlu zeminler üzerine oturan şerit bir temelden dolayı zemin içinde oluşan ilave düşey gerilme davranışları laboratuvar model deneyleri yapılarak araştırılmış ve ilk donatı tabakasının optimum derinliği, yükleme ve gerilme açısından deneysel olarak belirlenmiştir. Daha sonra, farklı temel şekillerinin, ilk donatı tabakasının optimum derinliğine etkisini belirleyebilmek amacıyla, yapılan bu çalışma literatürle [12-15] karşılaştırılmıştır.

\section{2. ÖNCEKİ ÇALIŞMALAR}

Zeminlerde oluşan düşey ve yatay gerilmelerin önemi bilindiğinden bunların belirlenmesi için birçok deney düzeneği ve tekniği geliştirilmiştir. $\mathrm{Bu}$ bölümde, düşey ve yatay gerilmelerin belirlenmesine yönelik 1920'lerden günümüze kadar yapılmış çalışmalar ve son yıllarda git gide önem kazanan zemin iyileştirme yöntemlerinden donatılı zemin uygulamaları ile ilgili çalışmalara yer verilmiştir.

Terzaghi [5], kil ve kum numunelerde düşey yüklerden dolayı oluşan yatay ve düşey gerilmeleri üretmiş olduğu deney düzeneğiyle ölçmüştür. Sonuçta, ölçmüş olduğu yatay ve düşey gerilmeleri oranlayarak, sükunetteki yanal zemin basınç katsayısı Donath [6], $\mathrm{K}_{0}$ değerlerini elde etmiş ve kaba kum için $\mathrm{K}_{0}=0,42$ değerini belirlemiştir [7].

Hanna ve Ghaly, kum zeminlerde yatay ve düşey gerilmeleri, basınç algılayıcı yardımıyla ölçmüşlerdir. Ölçülen sonuçlar ile Jaky [8] tarafından verilen $\mathrm{K}_{0}=1-\sin \phi$ değerleri ile karşılaştırılmıştır. Sonuçta, sıkılığın artmasına bağlı olarak deneysel ve teorik $\mathrm{K}_{0}$ değerlerinin azaldığını belirlemişlerdir. Ayrıca, ölçülen ilave gerilmelerin teorik değerlerden daha büyük değerler olduğu görülmüştür [7].

Keskin ve arkadaşları [9], kumlu zeminlerde, düşey yüklü kare temellerin merkezi altında oluşan ilave düşey gerilme değerlerini deneysel ve sayısal olarak araştırmışlardır. Sayısal analizlerde, zemin lineer elastik ve non-lineer elasto-plastik malzeme olarak modellenerek, analizlerde kullanılan bu modellerin ilave düşey gerilme değerlerine etkisi araştırılmıştır. Sonuçta, sonuçlar arasında bazı 
derinliklerde uyum içinde olduğu belirlenmiştir [9].

Bağrıaçık ve Laman [10], temellerin şekil etkisini araştırabilmek amacıyla, kumlu zeminler üzerine oturan farklı geometrilere sahip yüzeysel temellerden dolayı, zemin içinde oluşan ilave düşey gerilme davranışlarını laboratuvar model deneyleri ile belirlemişlerdir. Sonuçta, farklı geometrilerdeki temellerde şekil etkisinin önemli mertebelerde olduğu görülmüştür [10].

Bağrıaçık ve Laman [11], donatısız ve donatılı kumlu zeminler üzerine oturan yüzeysel bir temelden dolayı zemin içinde oluşan ilave düşey gerilme davranışlarını, model deneylerle araştırmıştır. Sonuçta, donatılı durumlardaki ilave düşey gerilmelerin, donatısız duruma göre, \%27 mertebelerinde fazladan azaldığı görülmüştür [11].

Bağrıaçık ve arkadaşları [12], donatı ile güçlendirilmiş kare bir temel altındaki zeminlerde optimum ilk donatı tabakası derinliğini, yükleme ve gerilme açısından belirleyebilmek amacıyla laboratuvar model deneyleri gerçekleştirmişlerdir. Deneylerde, sabit derinlikte bir kum tabakası hazırlanmış ve kare temelden dolayı oluşan donatısız durumda, kare temel genişliğinin 2 katı derinlikte meydana gelen gerilme değerleri ölçülmüştür. Sonuçta, kare temellerde ilk donatı tabakasının optimum derinliği, kare temel genişliğinin 0.40 katı olarak belirlenmiştir [12].

Örnek ve arkadaşları [13], kumlu zeminlere oturan eksantrik yüklü şerit temellerin davranışlarını belirleyebilmek amaciyla laboratuvar model deneyleri gerçekleştirmişlerdir. Sonuçta, yük eksantirisitesi arttıkça nihai taşıma gücünün azaldığı görülmüştür [13].

Türedi ve Örnek [14], dikdörtgen temelin farklı yükleme koşullarında zemine oturması sonucunda meydana gelen düşey gerilmeleri belirleyebilmek amacıyla model deneyler gerçekleştirmişlerdir. Ayrıca, deney sonuçlarını literatürdeki teorik yöntemlerle (Boussinesq, Westergaard ve 2:1 Yöntemi vb.) karşılaştırmışlardır. Sonuçta, eksantirisite arttıkça taşıma gücü değerlerinin azaldığı, temel merkezinden uzaklaşıldıkça da gerilme değerlerinde azalmalar tespit etmişlerdir.

Ayrıca, model deney sonuçları ile teorik sonuçların da birbirleri ile uyumlu olduklarını belirlemişlerdir [14].

Bağrıaçık [15], donatı ile güçlendirilmiş dairesel bir temel altındaki zeminlerde optimum ilk donatı tabakası derinliğini, yükleme ve gerilme açısından belirlemiştir. Deneylerde, sabit derinlikte bir kum tabakası hazırlanmıştır. Dairesel temele gelen düşey yüklerden dolayı oluşan zemin içindeki gerilme değerleri, güçlendirilmemiş ve geogrid donatılı ile güçlendirilmiş durumlarda, dairesel temel çapının 2 katı derinliğinde ölçülmüştür. Sonuçta, dairesel temellerde ilk donatı tabakasının optimum derinliği, dairesel temel genişliğinin 0,35 katı olarak belirlenmiştir [15].

\section{MATERYAL METOD}

Deneysel çalışmalar, Çukurova Üniversitesi İnşaat Mühendisliği Bölümü Zemin Mekaniği Laboratuvarında gerçekleştirilmiştir.

Kum numune üzerinde endeks ve mukavemet özelliklerini belirleyebilmek amacıyla yapılan deneylere göre, deney kumunun, zemin sınıfı, TS 1500 'e göre uniform temiz kum (SP) olarak belirlenmiştir (Çizelge 1).

Çizelge 1. Zemin özellikleri [11]

\begin{tabular}{|l|c|c|}
\hline Granülometri Parametreleri & Birim & Değer \\
\hline Orta Kum Yüzdesi & $\%$ & 46,40 \\
\hline İnce Kum Yüzdesi & $\%$ & 53,60 \\
\hline Efektif Dane Çapı, $\mathrm{D}_{10}$ & $\mathrm{~mm}$ & 0,18 \\
\hline $\mathrm{D}_{30}$ & $\mathrm{~mm}$ & 0,30 \\
\hline $\mathrm{D}_{60}$ & $\mathrm{~mm}$ & 0,50 \\
\hline Üniformluk Katsayısı, $\mathrm{C}_{\mathrm{u}}$ & - & 2,78 \\
\hline Derecelenme Katsayısı, $\mathrm{C}_{\mathrm{c}}$ & - & 1,00 \\
\hline Zemin Sınıfı & - & $\mathrm{SP}$ \\
\hline $\begin{array}{l}\text { Maksimum kuru birim } \\
\text { hacim ağırlık }\end{array}$ & $\mathrm{kN} / \mathrm{m}^{3}$ & 17,06 \\
\hline $\begin{array}{l}\text { Minimum kuru birim hacim } \\
\text { ağırlık }\end{array}$ & $\mathrm{kN} / \mathrm{m}^{3}$ & 15,03 \\
\hline Dane Birim Hacim Ağırlık & $\mathrm{kN} / \mathrm{m}^{3}$ & 26,80 \\
\hline
\end{tabular}


Deneysel çalışmalarda, $50 \mathrm{~cm}$ x $50 \mathrm{~cm} \mathrm{x} 40 \mathrm{~cm}$ boyutlarındaki kare kesitli bir kasa kullanılmıştır. Deney kasası iskeleti çelik profillerden olup, ön ve arka yüzü $6 \mathrm{~mm}$ kalınlığında cam, yan yüzeyler ile alt taban ise, $20 \mathrm{~mm}$ kalınlığındaki ahşap malzemeden imal edilmiştir [11].

Deneysel çalışmada, $10 \mathrm{~cm}$ genişliğe sahip olan şerit temel kullanılmıştır. İnşaat Mühendisliği Bölümü Zemin Mekaniği Laboratuvarındaki yükleme kirişine monte edilmiş, farklı yükleme hızlarında çekme ve basınç uygulayabilen yükleme düzeneği ile deneyler gerçekleştirilmiştir.

Temel plakasına gelen yük değerlerini belirlemek amaciyla ESIT firması tarafindan üretilen elektronik yük hücresi kullanılmıştır [16]. Zeminde meydana gelen düşey gerilmeleri ölçmek için $200 \mathrm{kPa}$ kapasiteli TML markalı basınç algılayıcılar kullanılmıştır [11].

Üretici firmadan temin edilen Çizelge 2'de teknik özellikleri yer alan geogrid donat1, temel tabanından itibaren farklı derinliklere $(\mathrm{U}=0,10 \mathrm{~B}$, $\mathrm{U}=0,15 \mathrm{~B}, \mathrm{U}=0,20 \mathrm{~B}, \mathrm{U}=0,25 \mathrm{~B}, \mathrm{U}=0,30 \mathrm{~B}, \mathrm{U}=0,35 \mathrm{~B}$ ve $U=0,40 B)$ Şekil 2'de görüldüğü gibi yerleştirilerek $\mathrm{Z}=2,0 \mathrm{~B}$ derinlikte meydana gelen gerilme değerleri ölçülmüştür.

Çizelge 2. Geogrid özellikleri [11]

\begin{tabular}{|l|c|c|}
\hline Teknik Özellikler & Birim & Secugrid \\
\hline Malzeme & - & Polipropilen \\
\hline $\begin{array}{l}\text { Maks. Çekme } \\
\text { Dayanımı, md/cmd* }\end{array}$ & $\mathrm{kN} / \mathrm{m}$ & $\geq 60 / \geq 60$ \\
\hline $\begin{array}{l}\% 2 \text { uzamada çekme } \\
\text { dayanımı, } \mathrm{md} / \mathrm{cmd}^{*}\end{array}$ & $\mathrm{kN} / \mathrm{m}$ & $22 / 22$ \\
\hline $\begin{array}{l}\% 5 \text { uzamada çekme } \\
\text { dayanımı, } \mathrm{md} / \mathrm{cmd}^{*}\end{array}$ & $\mathrm{kN} / \mathrm{m}$ & $48 / 48$ \\
\hline Açıklık, md $\times \mathrm{cmd}^{*}$ & $\mathrm{mmxmm}$ & $31 \times 31$ \\
\hline $\begin{array}{l}\text { Rulo genişliği / } \\
\text { uzunluğu }\end{array}$ & $\mathrm{mx} \mathrm{m}$ & $4,75 \times 100$ \\
\hline *md = machine direction $* \mathrm{cmd}=$ cross mach. \\
\hline
\end{tabular}

$* \mathrm{md}=$ machine direction, $* \mathrm{cmd}=$ cross mach.

Uygulanan düşey yükler, yük hücresi yardımıyla 8 kanal girişli ADU data logger cihazına aktarılıp, bu veriler daha sonra bilgisayar ortamında DIALOG programı yardımıla sayısal değerlere dönüştürülmüştür. Uygulanan düşey yüklerden dolayı meydana gelen düşey gerilmeler ise, basınç algılayıcıları yardımıyla, TML markalı taşınabilir data loggerdan elde edilmiştir [11].
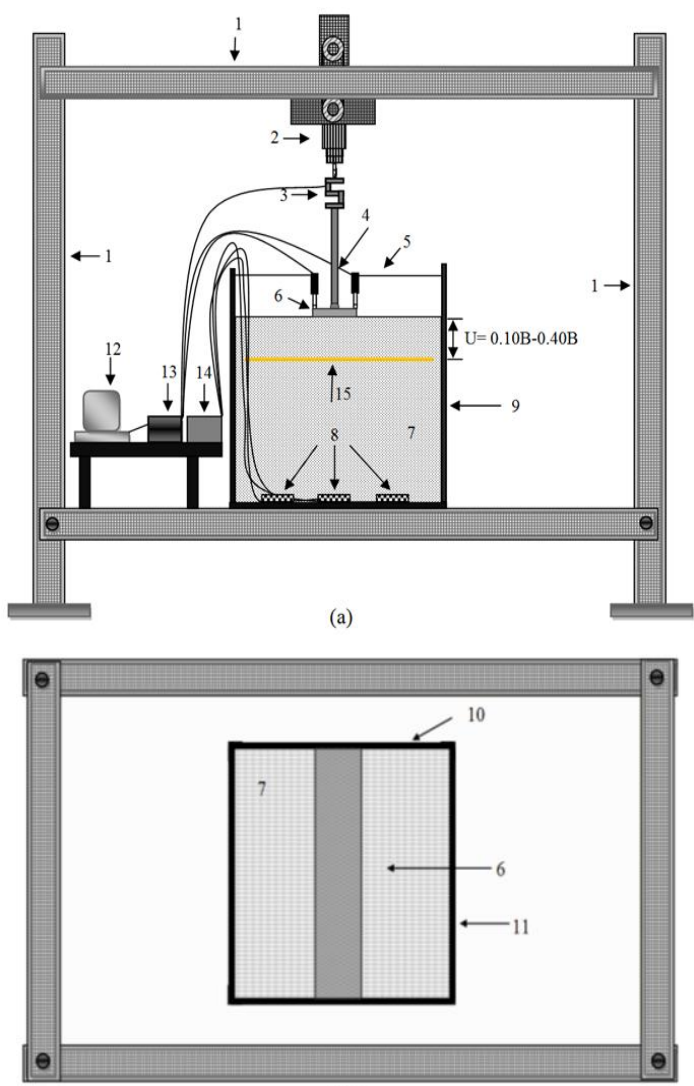

(b)

1-Yükleme Çerçevesi, 2-Motor Kontrollü Yükleme Sistemi, 3-Yük Hücresi, 4-Yükleme Başlığı, 5-Deplasman Ölçer, 6-Şerit Temel, 7-Model Zemin, 8-Basınç Algılayıcılar, 9-Deney Kasası, 10- Cam Tabaka, 11- Ahşap Tabaka, 12- Bilgisayar, 13- Veri Toplama Ünitesi (ELE), 14- Veri Toplama Ünitesi (TML), 15- Geogrid Donat1

Şekil 1. Deney düzeneği (a: Kesit, b: Plan)

Deney düzeneği Şekil 1'de gösterilmiş ve deneyler belirtilen hususlara dikkat edilerek gerçekleştirilmiştir. Basınç algılayıcıları deney kasasının içerisine deney esnasında hareket etmeyecek şekilde sabitlenmiş ve kum zemin, kasa içerisine tabakalar halinde belirlenen sıkılıkta $\left(\gamma_{\mathrm{k}}=15,03 \mathrm{kN} / \mathrm{m}^{3}\right)$ yerleştirilmiştir. 
Kum zemin tabakalar halinde yerleştirilirken, belirlenen derinliğe gelince geogrid donatı tabakası uygulanmıştır. Sıkıştırma işlemi tamamlandıktan sonra zemin üst yüzeyinin düzgünlüğü su terazisi ile kontrol edilerek, temel plakası zemin yüzeyine yerleştirilmiştir [16]. Uygulanan yükün, temel plakası merkezine düşey yönde etki ettirilmesine ve yükleme hızının her kademede sabit tutulmasına özen gösterilmiştir.

\section{BULGULAR VE TARTIŞMA}

\section{1. Şerit Temelde İlk Donatı Tabakasının Optimum Derinliğinin Belirlenmesi}

$\mathrm{Bu}$ çalışmada, donatı tabakası ile güçlendirilmiş bir kum tabakasında, şerit temelden dolayı oluşan, belirli derinlikte $(\mathrm{Z}=2.0 \mathrm{~B})$ meydana gelen gerilme değerleri ile güçlendirilmemiş durumda ölçülen gerilme değerleri karşılaştırılmıştır (U=geogridin temel tabanından itibaren derinliği, $B=$ temel genişliği, $\mathrm{Z}=\mathrm{kum}$ tabakası derinliği, $\mathrm{X}=$ temel merkezinden olan yatay mesafe).

Deney sonuçları, Şekil 2-10’da sunulmuştur.

Şekil 2-8'den uygulanan ilave düşey yükten kaynaklanan, $\mathrm{Z}=2,0 \mathrm{~B}$ 'de, donatılı ve donatısız durumlardaki gerilme değerlerinin değişimleri görülmektedir. Buradan, temel tabanından farklı derinliklere $(\mathrm{U}=0,10 \mathrm{~B}, \quad \mathrm{U}=0,15 \mathrm{~B}, \quad \mathrm{U}=0,20 \mathrm{~B}$, $\mathrm{U}=0,25 \mathrm{~B}, \mathrm{U}=0,30 \mathrm{~B}, \mathrm{U}=0,35 \mathrm{~B}$ ve $\mathrm{U}=0,40 \mathrm{~B}$ ) donat1 tabakası yerleştirilmesi durumunda, donatısız duruma göre temel merkezinde sırasıyla yaklaşık $\% 10,7, \% 27,2, \% 30,4, \% 38,2, \% 51,7, \% 52,9$ ve $\% 53,6$ oranlarında ilave gerilme azalmaları meydana gelmiştir. Aynı derinlikler için temel merkezinden yatay mesafede uzaklaştıkça da ilave gerilme değişimlerinin genel olarak benzer davranış gösterdiği belirlenmiştir.

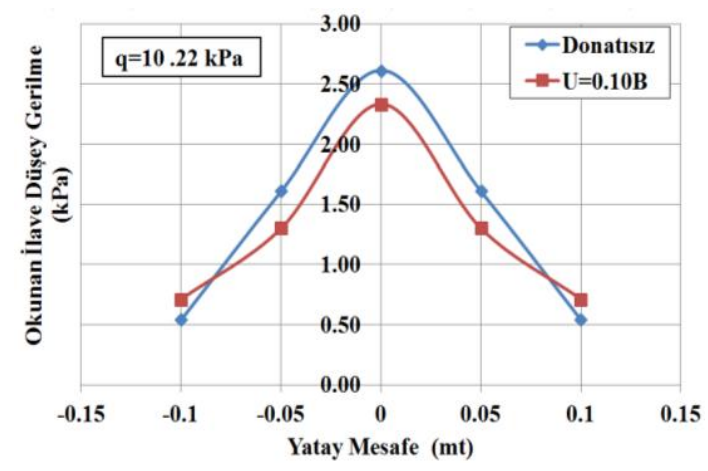

Şekil 2. U=0,10B için karşılaştırma

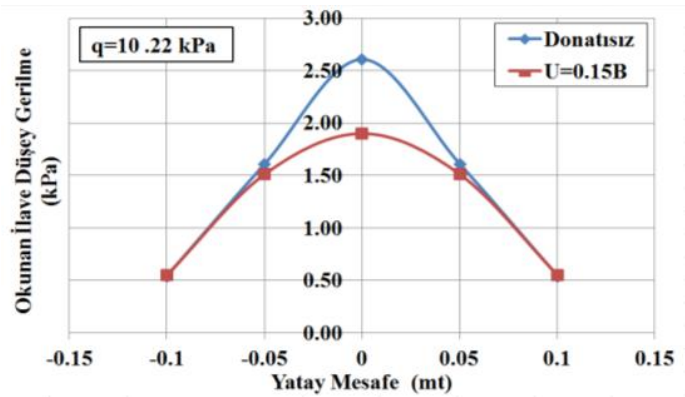

Şekil 3. $U=0,15 B$ için karşılaştırma

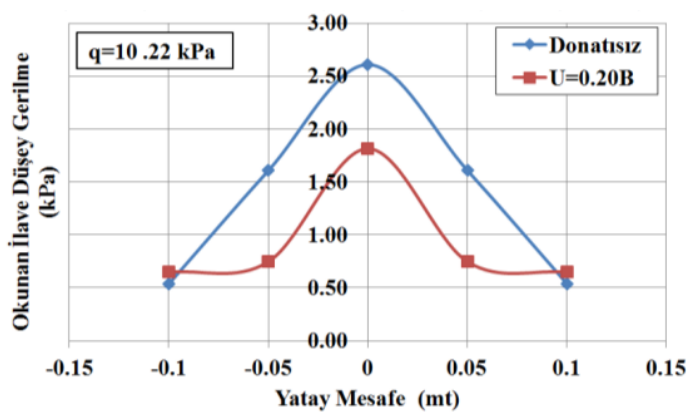

Şekil 4. $U=0,20 B$ için karşılaştırma

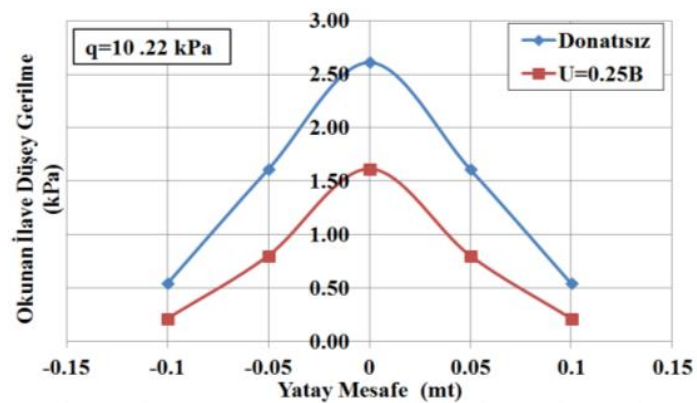

Şekil 5. $U=0,25 B$ için karşılaştırma 


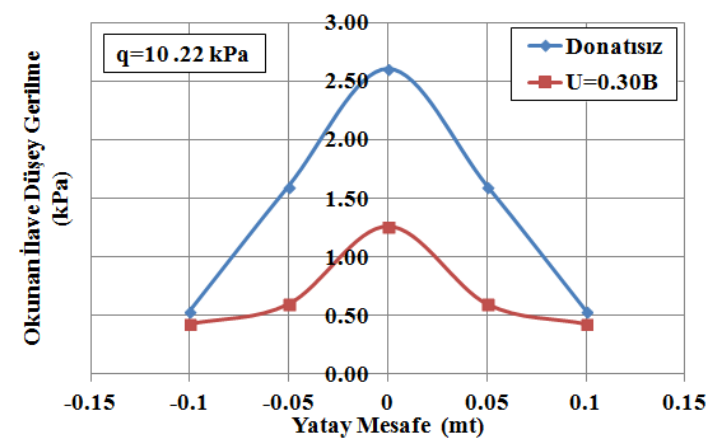

Şekil 6. $U=0,30 B$ için karşılaştırma

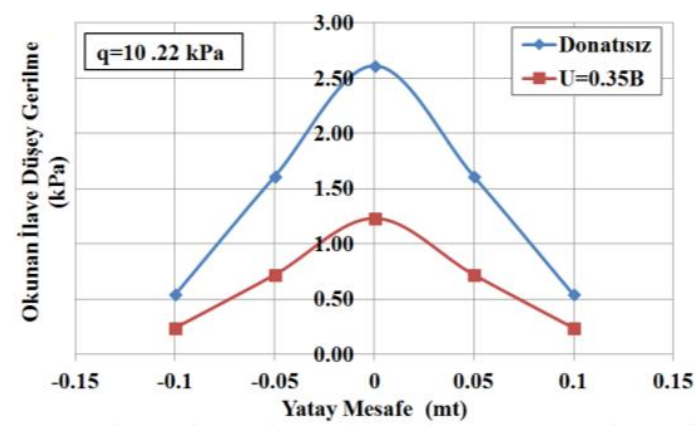

Şekil 7. U=0,35B için karşılaştırma

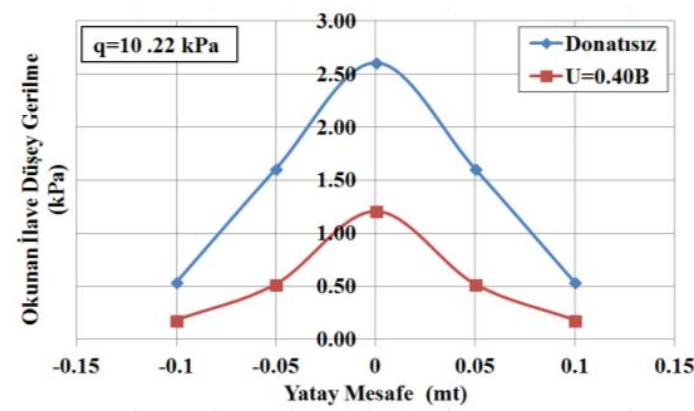

Şekil 8. U=0,40B için karşılaştırma

Şekil 9'da, farklı donatı tabakası derinliklerinde (U), $\sigma / q$ değerlerine (okunan ilave düşey gerilme/uygulanan ilave düşey gerilme) karşılık $\mathrm{X} / \mathrm{B}(\mathrm{X}=$ temel merkezinden olan yatay mesafe ve $\mathrm{B}=$ temel genişliği) görülmektedir. Buradan, temel merkezinden itibaren donatı tabakası derinliği arttıkça, $\sigma / q$ oranlarının hem temel merkezinde hem de temel merkezinden yatay mesafede uzaklaştıkça, belirli bir donatı tabakası derinliğine kadar azaldığ $1(\mathrm{U}=0,30 \mathrm{~B})$, bu derinlikten itibaren ise bu oranlarda kayda değer bir değişme belirlenememiştir.
Şekil 10'da, düşey eksen $\sigma / q$ ve yatay eksen U/B oranlarını göstermektedir. Sonuçta, temel merkezinde $\mathrm{U} / \mathrm{B}=0,30$ 'a kadar $\sigma / \mathrm{q}$ oranlarında azalmalar meydana geldiği, $\mathrm{U} / \mathrm{B}=0,30$ 'dan daha derinde bu azalmaların sabit kaldığı görülmüştür. Buna bağlı olarak, ilk donatı tabakasının optimum derinliği, şerit temel genişliğinin 0,30 katı $(\mathrm{U} / \mathrm{B}=0,30)$ olarak belirlenmiştir.

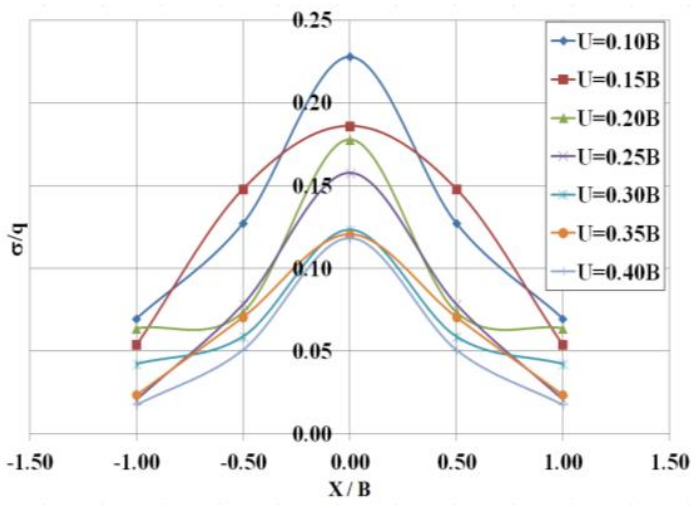

Şekil 9. Farklı donatı tabakası derinliğindeki $\sigma / \mathrm{q}$ oranlarının karşılaştırılması

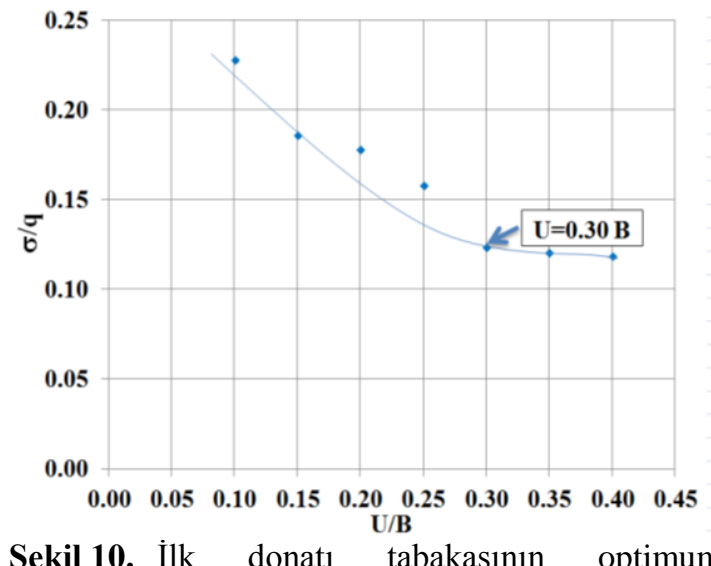

Şekil 10. İlk donatı tabakasının optimum derinliğinin belirlenmesi

\subsection{Farklı Temel Șekillerinin Etkisi}

Farklı temel şekillerinin, ilk donatı tabakasının optimum derinliğine etkisini bir arada gösterebilmek amacıyla, bu çalışma, Bağrıaçık ve arkadaşları [12] ve Bağrıaçık [15] tarafindan aynı 
koşullarda yapılmış olan çalıșmalarla karşılaştırılarak, sonuçlar Şekil 11'de sunulmuştur.

Şekil 11'den,

$>$ Kare temellerde ilk donatı tabakasının optimum derinliği, kare temel genişliğinin 0,40 katı [12],

$>$ Dairesel temellerde ilk donatı tabakasının optimum derinliği, dairesel temel çapının 0,35 katı [15],

$>$ Şerit temellerde ise ilk donatı tabakasının optimum derinliği, şerit temel genişliğinin 0.30 katı olarak belirlenmiştir.

Sonuçta, kohezyonsuz zeminlere oturan temellerin, şekillerinin farklı olması (kare, şerit veya dairesel temel vb.) ilk donatı tabakasının optimum derinliğini kayda değer bir şekilde etkilemektedir.

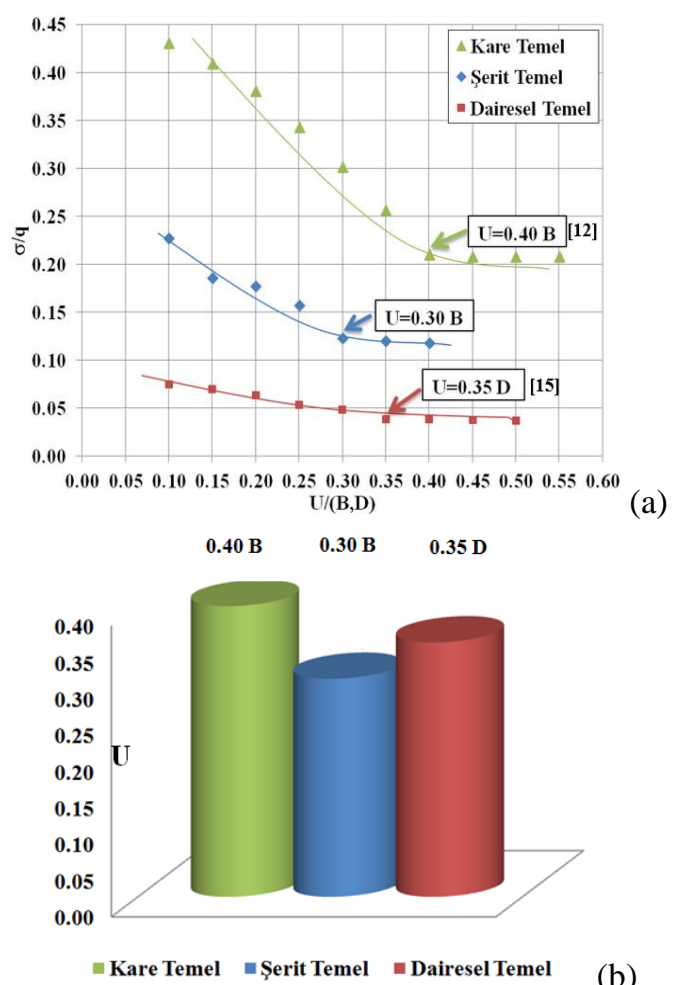

Şekil 11. Farklı temel şekillerinin ilk donatı tabakasının optimum derinliğine etkisi ( $\mathrm{U}=$ geogridin temel tabanından itibaren derinliği, $\mathrm{B}=$ temel genişliği, $\mathrm{D}=$ dairesel temel çapı)

\section{SONUÇLAR}

Uygulanan ilave düşey yük etkisinde, farklı derinliklere donatı tabakası yerleştirilmesi durumunda, donatısız duruma göre temel merkezinde sirasıyla yaklaşık \%10,7, \%27,2, $\% 30,4, \quad \% 38,2, \quad \% 51,7, \quad \% 52,9$ ve $\% 53,6$ oranlarında ilave gerilme azalmaları meydana geldiği belirlenmiştir.

$\mathrm{Bu}$ oranların, aynı derinlikler için temel merkezinden yatay mesafede uzaklaştıkça da temel merkezindeki davranışa yaklaşık olarak benzer sonuçlar elde edilmiştir.

Temel merkezinden itibaren donatı tabakasının derinliği arttıkça, gerilme değerlerinin ( $\sigma / q)$, belirli bir donatı tabakası derinliğine kadar azaldığı (U/B=0,30), bu derinlikten itibaren ise kayda değer bir azalmanın meydana gelmediği belirlenmiştir. Buna bağlı olarak ise ilk donatı tabakasının optimum derinliği, şerit temel genişliğinin 0,30 katı $(\mathrm{U} / \mathrm{B}=0,30)$ olarak belirlenmiştir.

Kohezyonsuz zeminlere oturan temellerin, şekillerinin farklı olması ilk donatı tabakasının optimum derinliğini (kare temel için: 0,40B [12], şerit temel için: $0,30 \mathrm{~B}$ ve dairesel temel için: 0,35D [15]) değiştirdiği gözlemlenmiştir.

\section{KAYNAKLAR}

1. Kumbasar, V., Kip, F., 1984. İnşaat Mühendisliğinde Zemin Mekaniği. Çağlayan Kitabevi, İstanbul, 350.

2. Uzuner, B.A., 1998. Çözümlü Problemlerle Temel Zemin Mekaniği, Teknik Yayınevi, Ankara.

3. Sağlamer, A., 1972. Kohezyonsuz Zeminlerde Sükunetteki Toprak Basıncı Katsayısının Zemin Parametreleri Cinsinden İfadesi, Doktora Tezi, İstanbul Teknik Üniversitesi, Fen Bilimleri Enstitüsü, İstanbul.

4. Demir, A., 2011. Yumuşak Kil Zemin Üzerinde Güçlendirilmiş Stabilize Dolguya Oturan Yüzeysel Temellerin Analizi, Doktora Tezi, Çukurova Üniversitesi, Adana. 
5. Terzaghi, K., 1920. Old Earth Pressure Theories and New Test Results, Engrg. NewsRec., 85 (14), 632-637.

6. Donath, A.D., 1891. Untersuchungen Veber den Erddruck auf Stuetzwaende. Zeitschrift fuer Bauwesen, Berlin, Germany.

7. Hanna, A., Ghaly, A., 1992. Effects of K0 and Overconsolidation on Uplift Capacity. Journal of Geotechnical Engineering, 118 (9), 1449. 1469.

8. Jaky, J., 1948. Pressure in Soils. Proc. 2nd Conf. On Soil Mech. and Found. Engrg., A.A. Balkema, Rotterdam, the Netherlands, 1, 103-107.

9. Keskin, M.S., Laman, M. Baran, T., 2008. Kuma Oturan Kare Temeller Altında Oluşan Düşey Gerilmelerin Deneysel Tespiti ve Sayısal Analizi, İMO Teknik Dergi, No 299. 4521-4538.

10. Bağrıaçık, B., Laman M., 2011. Investigation of the Shape Effect at Different Geometries on Stress Distribution of Sandy Soils pp. 78, International Balkans Conference on Challenges of Civil Engineering, BCCCE, 1921 May 2011, EPOKA University, Tirana, Albania.

11. Bağrıaçık, B., Laman M., 2011. Donatısız ve Donatılı Kumlu Zeminlere Oturan Dairesel Temeller Altında Gerilmelerin Değişimi. Gazi Üniversitesi Mühendislik Mimarlık Fakültesi Dergisi, Ankara, Vol:26, No:4, 787-800.

12. Bağrıaçık, B., Laman, M., Demir, A., 2012. Kare Temel Altındaki Zeminlerde Optimum Donatı Tabakası Derinliğinin Gerilme Yönünden İncelenmesi, 5. Ulusal Geosentetikler Konferansı, Boğaziçi Üniversitesi, İstanbul.

13. Örnek M., Türedi Y., Dal, K., 2014. Kum Zemine Oturan Eksantrik Yüklü Şerit Temellerin Analizi, Zemin Mekaniği ve Temel Mühendisliği 2. Özel Konulu Sempozyumu, 24-25 Nisan 2014, Antalya.

14. Türedi Y., Örnek M., 2015. Dikdörtgen Temel Altında Gerilme ve Taşıma Gücü Analizi, Çukurova Üniversitesi Mühendislik Mimarlık Fakültesi Dergisi, Cilt 30, (2) pp. 1-11.

15. Bağrıaçık, B., 2016. Dairesel Temel Altındaki Kum Zeminlerde Donatı Tabakasının Optimum Derinliğinin Belirlenmesi, Çukurova
Üniversitesi Mühendislik Mimarlık Fakültesi Dergisi, Cilt 31 (1) pp. 1-11.

16. Bağrıaçık, B., 2010. Zeminlerdeki Gerilme Durumlarının Deneysel ve Teorik Olarak İncelenmesi, Yüksek Lisans Tezi, Çukurova Üniversitesi, Adana. 